\title{
DETERMINANTS OF CHILDREN'S SCHOOL TRAVEL MODE USE IN DAR ES SALAAM
}

\author{
Hannibal Bwire ${ }^{1}$ \\ ${ }^{1}$ Department of Transportation and Geotechnical Engineering, Collège of Engineering and Technology, \\ University of Dar es Salaam, P.O.BOX 35131 Tanzania
}

Received 29 May 2020; accepted 28 June 2020

\begin{abstract}
Numerous factors affecting school children travel mode choice and usage have been reported in many studies. However, very little has been reported in similar studies undertaken in developing countries with little evidence from African cities where vehicle ownership is still very low and conditions in support of walking, cycling and public transport services are very poor. The study reported in this paper contains econometric analysis of school children's behaviour with regards to their choice between motorised transport and non-motorised transport modes for school travel in the Dar es Salaam city. Using data collected from an experimental survey, a binary Logit model and its marginal effects were estimated. The study reported in this paper attempts to add to the existing literature by providing additional insights into the association of some of the factors that have been reported in previous studies with motorised modes of travel and non-motorised modes which are commonly used by children to travel to/ from school in Dar es Salaam.
\end{abstract}

Keywords: econometric analysis, binary Logit model, motorized modes, non-motorised modes.

\section{Introduction}

Transport is an important component of the socioeconomic status of any country and a common tool used to facilitate socioeconomic development. This is even more so in a global economy where economic opportunities have been increasingly related to the mobility of people, goods and information. However, transport, especially in cities, causes a number of problems such as environmental problems and human health problems due to emissions of noise or vibrations, and road crashes. Walking and cycling modes cause virtually no noise or air pollution, and are ideal means of travel around cities. They don't require much space and are quite economical, costing much less than the car and public transport (Pucher and Dijkstra, 2000; Rwebangira, 2001; De Langen and Tembele, 2001), both in direct user costs and infrastructure provision costs (Pucher and Dijkstra, 2000). Despite the fact that the growth of cities and towns and the change of lifestyles and preferences have made it possible to have workplaces and residences in different locations, walking and cycling modes are still important modes of transport due to its positive impacts on the urban environment, transport system, safety, and health behaviours. Additionally, walking and cycling are even more important to children due to the fact that children are a growing population segment in

\footnotetext{
${ }^{1}$ Corresponding author: hbwire@udsm.ac.tz
} 
many urban areas around the world. In terms of transport, however, children are an overlooked and vulnerable population segment especially in developing countries. Europe, New Zealand and the US have long recognised the importance of cycling and walking to school trips. These countries have implemented a wide range of measures to improve safety of routes to school and as a result, they have developed the necessary technology and methods for implementation of cycling and walking programmes (Pucher and Dijkstra, 2000). Likewise, it is from the aforementioned countries where numerous studies and hence literature can be found on factors affecting school travel mode choice (Beck et al., 2008). Subsequently, a considerable amount of research aimed at studying children's school travel mode choice behaviour has been conducted in these countries. Consequently, numerous factors affecting school travel mode choice have been identified.

Existing studies show that travel distance, and hence travel time, has been found to be the most significant determinant factor in the school travel mode choice (Ermagun and Samimi, 2012; McDonald, 2008; McMillan, 2007; Ewing et al., 2004; Cervero and Duncan, 2003). Studies conducted by Krizek (2003) and McCormack et al. (2008) have shown that a distance of $400 \mathrm{~m}$ which is about five-minute walk is often used as an acceptable walking distance. McMillan (2007) observed that school children who live within $1.6 \mathrm{kms}$ from their school are more likely to choose non-motorised modes of transport than those who live farther than $1.6 \mathrm{~km}$ from school. This is because many school children are not willing to walk long distances and therefore are much more sensitive to walk travel time than car travel time. Ewing et al. (2004) found that school children with shorter walk and bike times to and from school are more likely to walk and bike. Generally, as reported by Hatamzadeh et al. (2017) travel distance has a negative sign in school travel mode choice models and diversely affects walking tendency.

Age has also been reported as an important determinant of walking travel behaviour. Some previous studies have shown that the age variable has a significant and negative effect on walking mode (McDonald, 2008; Wilson et al., 2010), while other studies found that the probability of choosing walking and cycling increases as age increases (Yeung et al., 2008; Pabayo et al., 2011; Su et al., 2013). McDonald (2008) noted that the probability of choosing walking declines when children get older (during high school) but with insignificant effect, while the age variable was only significant for children between 5 and 14 years (elementary and middle school children). However, studies such as Hatamzadeh et al. (2017) found that the age variable has a significant and negative effect on walking to school among high school students, but no significant effect on walking mode choice of children between 5 and 14 years. Other studies such as Ermagun and Samimi (2012) found no significant relation between age and choosing non-motorised modes of transport for school travel.

Gender has also been noted to be a significant factor on walking behaviour of school children. Many studies on school travel have found that girls are less likely to walk than boys (Cooper et al., 2003; Marten and Olds, 2004; McMillan et al., 2006; McDonald, 2008; Johnson et al., 2010; Hatamzadeh et al., 2017). Additionally, Evenson et al. (2003 observed that rates of walking were generally higher for older boys (in high school) who had a lower body mass index and had 
parents that were infrequently home after school. However, studies done by Wilson et al. (2010), Ermagun and Samimi (2012), Bopp et al. (2012) do not support the finding that boys are more likely to walk to school than girls, while other studies on elementary school children travel behaviour have found no relation between gender and children's walking to school (Su et al., 2013; Carlin et al., 1997). Su et al. (2013) argued that gender differences at the age for elementary school may not yet be a determinant factor in influencing children's walking to school rates.

There are also some studies that have investigated the effects of household socioeconomic characteristics on the use and choice of transport modes of school children. Numerous studies such as Spallek et al. (2006), McMillan (2007), Pabayo et al. (2011) and Ermagun and Samimi (2012) have shown that children of parents with lower income level are more likely to choose walking and cycling modes for school travel than those with higher income. Other studies (Copperman and Bhat, 2007; Wilson et al., 2010; Mackett, 2011; Park et al., 2013), have reported households' access to private cars with a negative effect on non-motorised modes of transport for school travel. McMillan (2007) observed that the number of cars per driver in the household had no effect on the school travel mode choice. Ewing et al. (2004) found that students from households with more vehicles per capita and higher incomes are less likely to walk to school than to take a car, school bus or bicycle. This result is supported by Hatamzadeh et al. (2017) who reported that regardless of age, school children who have a car in their household are less motivated to walk to school.
The influence of the built environment and urban form on school travel mode choice have also been investigated. The results are somehow mixed; the built environment has been found to exert a small, but significant, effect on walking to school (McDonald, 2008). Srinivasan and Rogers (2005) found the location to be one of the factors influencing travel mode choice. Braza et al. (2004) found that walking and biking rates were associated with neighbourhood density (positively) and school size (negatively). Similarly, it has been found that urban form variables have a relatively less impact on mode choice compared to other variables like socioeconomic attributes, distance, and vehicular traffic conditions (McMillan et al., 2006). Boarnet et al. (2005) found a sidewalk improvement, crossing improvements and traffic control enhancements, increased walking and cycling among school children. Likewise, Ewing et al. (2004) found the street sidewalk coverage to have the most significance influence on walking. However, they also found that none of the other urban form variables that proved important in earlier studies, such as neighbourhood population density and street tree coverage, proved significant.

Other factors influencing children travel behaviour include traffic safety and parental perception about traffic danger and the risk of abduction or harassment (McDonald, 2008). Ridgewell et al. (2009) noted that perceived stranger danger or a danger of assault and the danger from the increase in traffic as the most significant factors influencing the choice of car instead of bicycles for school trips. Transport mode safety plays a significant role in mode choice for many parents as they believe that driving 
children to school is safer than having them use non-motorized transport modes (Rhoulac, 2005).

On the other hand, few studies have provided some insights into children's travel to school in Africa. For instance, AU et al. (2005), Porter and Blaufuss (2002) and Porter et al. (2011) noted that the majority of children in Africa travel to/from school on foot. AMEND and FIA (2016) observed that Africa has the most dangerous roads in the world. This is due to the neglect of pedestrians, absence of footpaths and safe crossings, the poor management or maintenance of those footpaths that do exist, the lack of street lighting, and the lack of speed control. Porter et al. (2011) also observed that the journey to school is usually perceived by parents and children to be hazardous due to the potential for human attack and harassment. Further, Porter et al. (2011) observed that parents or guardians in some African countries encourage their children to travel in a group so as to be sure of their safety and security. This result mirrors findings from Bwire et al. (2017) who reported that children felt safer when using the walking bus and cycle trains in their journey to or from school.

Nevertheless, walking is still the dominant mode of travel in African cities. In 2015, the Sub-Saharan African Transport Policy Programme (SSATP) reported that walking makes up between $50 \%$ and $90 \%$ of daily trips (SSATP, 2015), while cycling constitutes a low percentage of trips varying between $0.05 \%$ and $2 \%$. Additionally, a survey administered in 2008 by the African Centre of Excellence for Studies in Public and Non-Motorised Transport (ACET) formed by the three partner universities of Cape Town, Dar es Salaam and Nairobi
- revealed that NMT as a main mode for travel accounts for $33.9 \%$ of all trips in Cape Town ( $n=2002$ households), while Dar es Salaam ( $n=2009$ households) and Nairobi ( $n=2002$ households) have $48.4 \%$ and $61.3 \%$, respectively (Vanderschuren and Jennings, 2017 in Mitullah et al., 2017). The ACET study also showed that NMT is a dominant mode of travel to education places in all three cities. In Cape Town, $59.2 \%$ of travellers use NMT as their only (main) mode of travel to educational places, while $48.6 \%$ and $68.9 \%$ use only NMT in Dar es Salaam and Nairobi, respectively. Other studies have found that private school children rely extensively on motorized transport modes as compared to non-motorized modes in public schools (Adom-Asamoah et al., 2015; Porter and Blaufuss, 2002). A very recent study of revision of Dar es Salaam urban transport master plan by MoWTC and JICA (2018) showed that NMT as a main mode of travel accounted for $39.5 \%$ of all trips, motorcycle $4.9 \%$, car $3.7 \%$ and public transport (BRT, Daladala, bus, ferry and train) $51.9 \%$. For school trips, it was revealed that $60.3 \%$ of school trips are made on foot and by cycling, while the remaining trips are made by motorcycle $2.2 \%$, car $0.7 \%$, public transport modes (BRT, Daladala, bus, ferry and train) $36.8 \%$.

Numerous studies have evaluated the effect of a wide range of factors affecting children's school travel mode choice and suggested a range of policy measures for the decisionmakers. Overall, previous studies usually focus on research on school children and walking, cycling and car travel modes. However, the study reported in this paper attempts to add to the existing literature by providing additional insights into the association of some of the factors that have been reported in previous studies with 
motorised modes of travel (car and public transport modes - paratransit/Daladala bus services, school bus and motorcycle taxi) and non-motorised modes (walking and cycling), which are commonly used by children to travel to/ from school in Dar es Salaam.

\section{Data and Methodology}

\subsection{Data}

The study utilised data from the database that was created from a survey that was carried out between September and November, 2011 using a pen and paper selfcompletion questionnaire. The survey was completed by school children either at home with the help of parents/guardians or in class, depending on class teacher preference. Notes and instruction regarding the purpose of the research and the meaning of questions were provided during the survey, which used crosssectional research design to explore factors influencing children's choices of school travel mode in Dar es Salaam. Apart from questions related to walking bus and cycle train, the survey instrument also had survey questions focusing on information about the child and parent/ guardian (age, gender, mode of travel to/ from school, reasons for not walking or cycling, distance to school, income group of parents/ guardians and car availability). It is this part of the travel survey data which is being analysed in this paper for school children between 5 and 15 years (primary school children). Survey data on walking bus and cycle train is analysed and discussed in Bwire et al. (2017) in Mitullah et al. (2017).

Tables 1 and 2 present summary statistics of the survey data analysed in this paper. It can be seen from Table 1 that the data contain $46.6 \%$ of girls and $53.4 \%$ of boys. The tables also show some descriptive statistics on safety concerns, household monthly income, parents'/guardians' employment status and car availability. Table 2 shows that $64.8 \%$ of the school children walked/ cycled to school, a result which is not much different from the very recent modal split results; $60.3 \%$ reported by MoWTC and JICA (2018). Additionally, this result is also within the range of modal split reported by SSATP (2015) for Africa.

Table 1

Summary of School Children Travel Statistics used in Modelling

\begin{tabular}{|c|c|c|}
\hline \multicolumn{2}{|c|}{ Item } & Number (\%) \\
\hline \multirow{2}{*}{ Gender } & Male & $373(46.6)$ \\
\cline { 2 - 3 } & Female & $428(53.4)$ \\
\hline \multirow{2}{*}{ Safety } & Unsafe due to too many vehicles on the road & $95(11.9)$ \\
\cline { 2 - 3 } & Unsafe due to other reasons & $708(88.1)$ \\
\hline \multirow{3}{*}{ Monthly Income } & Less than 300,000/= Tshs. (115.25 EUR) & $569(71.0)$ \\
\cline { 2 - 3 } & 300,000/=-1,000,000/= Tshs. (115.25 - 384.16 EUR) & $150(18.7)$ \\
\cline { 2 - 3 } Employment & $1,000,000 /=-1,500,000 /=$ Tshs. $(384.16-576.24$ EUR $)$ & $32(10.2)$ \\
\cline { 2 - 3 } & Employed/ self-employed & $351(43.8)$ \\
\hline \multirow{3}{*}{ Car availability } & Unemployed & $450(56.2)$ \\
\cline { 2 - 3 } & 0 cars & $315(14.4)$ \\
\cline { 2 - 3 } & 1 car & $320(39.9)$ \\
\hline
\end{tabular}

$N=801$ 
Additionally, Table 2 shows that at a distance less than $3.0 \mathrm{~km}$, walking most of/all the way is most widely used by school children to travel to/from school and beyond this distance motorised transport modes, and more particularly Daladala is more widely used for school travel. Some school children do walk and cycle over greater distances than $5.0 \mathrm{~km}$, even if cycling and walking seem to be an unattractive travel option among the children at distances of $3.0 \mathrm{~km}$ and beyond. Further, Table 2 shows that even at a distance less than 1.0 $\mathrm{km}$ Daladala, and in general motorized transport is commonly used by some school children.

\section{Table 2}

School Travel Mode Use Characteristics (in Number of Respondents)

\begin{tabular}{|c|c|c|c|c|c|c|c|c|}
\hline 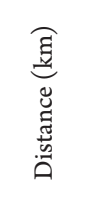 & 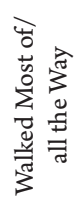 & 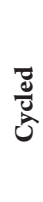 & 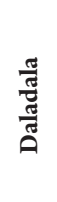 & 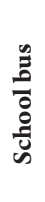 & 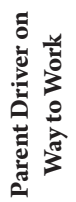 & 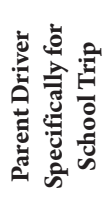 & 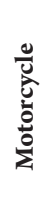 & సี \\
\hline$<0.5$ & 70 & 06 & 25 & 0 & 3 & 1 & 2 & 107 \\
\hline $0.5-1.0$ & 152 & 13 & 13 & 2 & 4 & 0 & 2 & 186 \\
\hline $1.0-2.0$ & 72 & 15 & 31 & 2 & 3 & 3 & 2 & 128 \\
\hline $2.0-3.0$ & 47 & 13 & 25 & 1 & 3 & 0 & 1 & 90 \\
\hline $3.0-4.0$ & 21 & 7 & 30 & 3 & 2 & 0 & 1 & 64 \\
\hline $4.0-5.0$ & 39 & 1 & 29 & 1 & 2 & 0 & 3 & 75 \\
\hline$>5.0$ & 56 & 7 & 72 & 4 & 9 & 10 & 2 & 151 \\
\hline Total & 457 & 62 & 225 & 13 & 26 & 5 & 13 & 801 \\
\hline
\end{tabular}

\subsection{Methodology}

Binary choice (MT - motorized transport modes and NMT - non-motorised transport modes) was considered, and each choice has four categories of variables as shown in Table 3.

\section{Table 3}

Variables Definition for Binary Logit Model Estimation

\begin{tabular}{|c|c|}
\hline $\begin{array}{c}\text { Description of Variable } \\
\text { Categories }\end{array}$ & Variable Name \\
\hline Modes & NMT (walking and cycling) and MT (car, Daladala, school bus and motorcycle) \\
\hline \multirow{3}{*}{ Travel Characteristics } & Travel time (continuous variable) \\
\cline { 2 - 2 } & Safety (1=unsafe because of traffic volume; $2=$ unsafe because of other reasons) \\
\cline { 2 - 2 } Child Characteristics & Distance (continuous variable) \\
\cline { 2 - 2 } & Gender (1=Male; $2=$ Female) \\
\hline \multirow{3}{*}{$\begin{array}{c}\text { Household Socio-economic } \\
\text { Characteristics }\end{array}$} & Age (5 to 15 years) \\
\cline { 2 - 2 } & Household income (continuous variable) \\
\cline { 2 - 2 } & Car availability (0 = No; $1=$ Yes) \\
\hline
\end{tabular}


Travel modes were considered as dependent variables and travel, child as well as household socioeconomic characteristics were considered as independent variables. The MT category covered Daladala, school bus and car modes, while the NMT covered walking and cycling. A binary Logit model was used to investigate the influence of variables affecting the choice and usage of MT and NMT modes, and determine the probability of choosing a mode.

\subsection{Study Limitations}

The analysis results are not regarded as fully representative of all school children in Dar es Salaam city, nor of the participating schools in the study area for the following reasons. The number of sampled primary schools and secondary schools represents $1.2 \%$ and $1.0 \%$ of all primary and secondary schools in the city, respectively, and only $12.8 \%$ of the total school children population of the selected schools participated in the survey and therefore it cannot be claimed that the results of the study are representative of all school children. Moreover, the majority of children who participated in the survey belonged to primary school classes 4,5 and 6 as well as Form 2 and Form 3 in secondary schools. Thus, the selection of the children may have introduced some bias. On the other hand, the choice of schools surveyed were only those that had already received cycling and road safety training.

\section{Results and Discussion}

As it can be noted from Table 4, all significant coefficients in the model have expected sign and they are in agreement with the actual condition of the case study area and the existing literature. The distance variable contributes greatly to a decision to use MT mode (Daladala and School bus). The variable increases the utility associated with the choice and or use of public buses by 0.28163 to nonmotorised modes of transport. In effect, school children prefer MT modes (public transport modes) over NMT modes when encountering longer distances. Likewise, the time variable has a positive sign and increase the utility associated with the choice and usage of MT modes by 0.03002 .

Table 4

Binary Logit Model Estimation Results

\begin{tabular}{|c|c|c|c|c|c|c|}
\hline Choice & Variable & Coefficient & $\mathrm{Z}$ value & $\mathrm{P}>|\mathrm{Z}|$ & \multicolumn{2}{|c|}{ [95\% Conf. Interval] } \\
\hline \multirow{13}{*}{ MT } & Female & 0.24406 & 1.48 & 0.139 & -0.07935 & 0.56747 \\
\hline & Age & -0.06260 & -0.97 & 0.333 & -0.18933 & 0.06413 \\
\hline & Time & 0.03002 & 5.64 & 0.000 & 0.01959 & 0.04044 \\
\hline & Distance & 0.28163 & 6.43 & 0.000 & 0.19585 & 0.36741 \\
\hline & Unemployed & -0.13861 & -0.83 & 0.409 & -0.46785 & 0.19064 \\
\hline & Car available & 0.20485 & 0.8 & 0.423 & -0.29621 & 0.70590 \\
\hline & Unsafe (other reasons) & 0.15051 & 0.88 & 0.380 & -0.18560 & 0.48662 \\
\hline & Income & -0.00609 & -0.25 & 0.800 & -0.05328 & 0.04111 \\
\hline & Constant & -1.58510 & -1.85 & 0.064 & -3.26463 & 0.09444 \\
\hline & Number of observations & 801 & & & & \\
\hline & Prob $>\chi^{2}$ & 0.000 & & & & \\
\hline & Likelihood $\chi^{2}$ & 112.04 & & & & \\
\hline & Pseudo $\mathrm{R}^{2}$ & 0.1099 & & & & \\
\hline
\end{tabular}


However, female, age, unemployment and non-availability of car, safety concerns about other issues other than traffic volume, and income variables are insignificant. Even though insignificant the negative sign associated with age, unemployment and income shows that an increase of these variables will result in the disutility of MT modes. This means that as age increases children are motivated to use NMT modes over MT modes. Although the age variable is insignificant, this result is not in line with previous findings reported by $\mathrm{McD}$ onald (2008), Wilson et al. (2010) and Hatamzadeh et al. (2017). However, the result supports the findings reported by Yeung et al. (2008) Pabayo et al. (2011) and Su et al. (2013). The results also show that school children whose parents and or guardians are unemployed are less likely to use MT over NMT modes. Although the household income variable is also insignificant, it is surprising to note that it has a negative effect on the use MT modes. An explanation behind this result could be due to a small sample of children who use car for school travel, while the majority use public transport, which in effect could be indicating that an increase in income is more likely to cause a reduction in public transport (Daladala, school bus and motorcycle) patronage among school children. A further explanation is that a reduction in trips by MT modes (Daladala, school bus, car use and motorcycle) may also be associated with the fact that children who would prefer to cycle do not have bicycle because they cannot afford to buy it. Therefore, an increase in income is likely to motivate them to acquire a bicycle.
On the other hand, the positive sign of insignificant variables (female, nonavailability of car and safety concerns due to non-traffic issues) shows that an increase of these variables will result in utility of MT modes. Even though insignificant the positive sign of female means that female school children would prefer to use MT modes over NMT modes, a result which resonates well with previous studies. Also, school children who do not have access to a car are more likely to use MT over NMT modes. This indicates that school children without access to a car are more likely to use public transport over NMT for school trips. Despite the insignificance, safety concerns due to non-traffic issues were more important than concerns due to traffic volume and have a positive effect on the utility of MT modes. The safety issue indicates that parents believe that it is safer for a child to travel to/from school by MT modes than having them use NMT modes in the unsafe road environment. This result is in line with previous findings (see, for instance, Rhoulac, 2005).

The results of the marginal effect from Table 5 show that an increase in distance and time variables increase the change in the probability of public transport mode patronage by 0.05385 and 0.00574 respectively and are all significant. Girls, non-availability of car and safety variables are insignificant even though they increase the change in the probability of public transport patronage, while age, unemployment and income decrease the change in the probability of public transport patronage. 
Table 5

Marginal Effects After Logit Model

\begin{tabular}{|c|c|c|c|c|c|c|}
\hline Choice & Variable & $\mathbf{d y} / \mathbf{d x}$ & $\mathbf{z}$ & $\mathbf{P}>|\mathbf{z}|$ & \multicolumn{2}{|c|}{ [95\% Conf. Interval] } \\
\hline \multirow{7}{*}{ Female } & 0.04665 & 1.48 & 0.138 & -0.01493 & 0.10824 \\
\cline { 2 - 7 } & Age & -0.01197 & -0.97 & 0.332 & -0.03616 & 0.01222 \\
\cline { 2 - 7 } & Time & 0.00574 & 6.07 & 0.000 & 0.00389 & 0.00759 \\
\cline { 2 - 7 } MT & Distance & 0.05385 & 7.12 & 0.000 & 0.03903 & 0.06868 \\
\cline { 2 - 7 } & Unemployed & -0.02650 & -0.83 & 0.409 & -0.08938 & 0.03638 \\
\cline { 2 - 7 } & Car available & 0.03834 & 0.82 & 0.412 & -0.05322 & 0.12990 \\
\cline { 2 - 7 } & Unsafe (other reasons) & 0.02868 & 0.88 & 0.378 & -0.03506 & 0.09242 \\
\cline { 2 - 7 } & Income & -0.00116 & -0.25 & 0.800 & -0.01019 & 0.00786 \\
\hline
\end{tabular}

\section{Conclusion}

This study sought to investigate the determinants of children's school travel mode choice between using an MT and NMT modes for school travel. The binary Logit model was employed to estimate the children's choices. The results show that children will resort to the use of NMT over MT modes when encountering longer distances. The result is in line with previous findings. However, female, age, unemployment and non-availability of car, safety concerns about other issues other than traffic volume, and income variables are insignificant, but some of findings support results reported in previous studies. The negative sign associated with age, unemployment and income shows that an increase of these variables will result in the disutility of MT modes. On the other hand, the positive sign of female, non-availability of car and safety concerns due to nontraffic issues shows that an increase of these variables will result in utility of MT modes.

Even though the age variable is insignificant, children are motivated to use NMT modes over MT modes as they get older.
This result is not in line with some of the previous findings. The study has also shown that school children whose parents and or guardians are unemployed are less likely to use MT modes. Although the household income variable is also insignificant, it is surprising to note that it has a negative effect on the use MT modes, which means that an increase in income is more likely to cause a reduction in trips by MT modes (Daladala, school bus, car use and motorcycle). This means that children who would prefer to cycle do not have bicycle because they cannot afford to buy it. Therefore, an increase in income is likely to enable them to acquire a bicycle. Moreover, despite the insignificance, safety concerns due to non-traffic issues were more important than concerns due to traffic volume and have a positive effect on the utility of MT modes. The safety issue indicates that parents believe that it is safer for a child to travel to/from school by MT modes than having them use NMT modes in the unsafe road environment.

One contribution of this study beyond that of other school children travel studies is the result which shows that even though the age variable is insignificant, children 
are motivated to use NMT modes over MT modes as they get older. Further, the negative effect of income on the use MT modes, shows that households with children who would prefer to cycle are more likely to acquire a bicycle for their children.

The findings of this study may be used by transport operators and policy makers to improve the level of public transport services and infrastructures for walking and cycling with a view to enhance the safety and security of NMT modes. Further, means should be sought for making bicycles affordable to a common household and a policy of establishing primary and secondary schools in every ward should be implemented fully, where its justifiable, so as to reduce travel distances to schools.

\section{Acknowledgements}

The data collection was funded by the Volvo Research and Educational Foundations (VREF) as part of a broader research programme conducted by the African Centre of Excellence for Studies in Public and Nonmotorised Transport (ACET, www.acet.uct. ac.za). The dataset was prepared in 2011 by Patrick Chacha whom the author of this paper worked with in the VREF funded ACET project. The corresponding author states that there is no conflict of interest.

\section{References}

Adom-Asamoah, G.; Okyere, S. A.; Senayah, E. A. K. 2015. Factors influencing school travel mode choice in Kumasi, Ghana, International Journal of Development and Sustainability 4(1): 1-17.
AMEND \& FIA. 2016. Step change: An action agenda on safe walking for Africa's children. Available from internet: <https://www.roadsafetyhub.com/ resources/42/report-fia-foundation-amend-reporton-child-pedestrians-in-africa.html>.

AU, UN, ADB, WB, EU. 2005. Transport and the millennium development goals in Africa. Available from internet: <http://www.worldbank.org/transport>.

Beck, L. F.; Greenspan, A. I. 2008. Why don't more children walk to school? Journal of Safety Research 39(5): 449-452.

Boarnet, M. G.; Anderson, C. L.; Day, C.; McMillan, T. E.; Alfonzo, M. 2005. Evaluation of the California safe routes to school legislation: urban form changes and children's active transport to school, American Journal of Preventive Medicine 28(2): 134-140.

Bopp, M.; T.Kaczynski, A.; Besenyi, G. 2012. Active commuting influences among adults, Preventive Medicine 54: 237-241.

Braza, M.; Shoemaker, W.; Seeley, A. 2004. Neighbourhood design and rates of walking and biking to elementary school, American Journal of Health Promotion 19(2): 128-136.

Bwire, H.; Muchaka, P.; Behrens, R.; Chacha, P. 2017. Implementation and evaluation of walking buses and cycle trains in Cape Town and Dar es Salaam. In Mitullah WV, Vanderschuren M and Khayesi M (eds) Non-Motorized Transport Integration into Urban Transport Planning in Africa, New York, Routledge, 150-168.

Carlin, J.B.; Stevenson, M.R.; Roberts, I.; Bennett, C.M.; Gelman, A.; Nolan, T. 1997. Walking to school and traffic exposure in Australian children, Australian and New Zealand Journal of Public Health 21: 286-292. 
Cervero, R.; Duncan, M. 2003. Walking, bicycling, and urban landscapes: Evidence from the San Francisco Bay Area, American Journal of Public Health 93(9): 1478-1483.

Cooper, A.R.; Page, A.S.; Foster, L.J.; Qahwaji, D. 2003. Commuting to school-are children who walk more physically active?, American Journal of Preventive Medicine 25(4): 273-276.

Copperman, R.; Bhat, C. 2007. An analysis of the determinants of children's weekend physical activity participation, Transportation 34(1): 67- 87.

De Langen, M.; Tembele, R. 2001. Productive and Liveable Cities: guidelines for pedestrian and bicycle traffic in African cities. Version 1.3. A.A. Balkema, Rotterdam. 430 p.

Ermagun, A.; Samimi, A. 2012. Active Transportation Mode Choice Behavior across Genders in School Trips. In Annual Meeting of the Transportation Research Board, Washington, D.C. 24 p.

Evenson, K.R.; Huston, S.L.; McMillen, B.J.; Bors, P.; Ward, D.S. 2003. Statewide prevalence and correlates of walking and bicycling to school, Archives of Pediatrics \& Adolescent Medicine 157(9): 887-892.

Ewing, R.; Schroeer, W.; Greene, W. 2004. School location and student travel analysis of factors affecting mode choice, Transportation Research Record: Journal of the Transportation Research Board 1895(1): 55-63.

Hatamzadeh, Y.; Habibian, M.; Khodaii, A. 2017. Effective factors in walking mode choice of different age groups for school trips, Transportation Research Procedia 25: 2297-2308.

Johnson, T.G.; Brusseau, T.A.; Darst, P.W.; Kulinna, P.H.; White-Taylor, J. 2010. Step counts of non-white minority children and youth by gender, grade level, race/ ethnicity, and mode of school transportation, Journal of Physical Activity \& Health 7(6): 730-736.
Krizek, K. 2003. Neighborhood services, trip purpose, and tour-based travel, Transportation 30(4): 387-410.

Mackett, R.L. 2011. Letting children be free to walk. In Proceedings of the WALK 21, 12th Annual Conference, Vancouver, Canada.

Marten, N.; Olds, T. 2004. Physical activity: patterns of active transport in 11-12 year old Australian children, Australian and New Zealand Journal of Public Health 28(2): 167-172.

McCormack, G.; Giles-Corti, B.; Bulsara, M. 2008. The relationship between destination proximity, destination mix and physical activity behaviors, Preventive Medicine 46(1): 33- 40 .

McDonald, N. C. 2008a. Children's mode choice for school trip: the role of distance and school location in walking to school, Transportation 35(1): 23-35.

McDonald, N. C. 2008b. Household interactions and children's school travel: the effect of parental work patterns on walking and biking to school, Journal of Transport Geography 16(5): 324-331.

McMillan, T. 2007. The relative influence of urban form on a child's travel mode to school, Transportation Research Part A-Policy and Practice 41(1): 69-79.

McMillan, T.; Day, K.; Boarnet, M.; Alfonzo, M.; Anderson, C. 2006. Johnny walk s to school-Does Jane? Sex differences in children's active travel to school, Children, Youth and Environments 16(1): 75-89.

Ministry of Work, Transport and Communication Tanzania (MoWT) \& Japanese International Cooperation Agency (JICA). 2018. The Projectfor Revision of Dar es Salaam Urban Transport Master Plan in United Republic of Tanzania. Unpublished Final Report - Main Text Volume-2, Dar es Salaam, Tanzania. 
Pabayo, R.; Gauvin, L.; Barnett, T.A. 2011. Longitudinal changes in active transportation to school in Canadian youth aged 6 through 16 years, Pediatrics 128(2): 404413.

Park, H.; Noland, R.B.; Lachapelle, U. 2013. Active school trips: associations with caregiver walking frequency, Transport Policy 29: 23-28.

Porter, G.; Hampshire, K.; Munthali, A.; Robson, E. 2011. Mobility, surveillance and control of children and young people in the everyday: Perspectives from sub-Saharan Africa, Surveillance \& Society 9(1/2): 114-131.

Porter, G.; \& Blaufuss, K. 2002. Children, transport and traffic in southern Ghana. In Proceedings of the International Conference on Children, Transport and Traffic, Copenhagen.

Pucher, J.; Dijkstra, L. 2000. Making Walking and Cycling Safer: lessons from Europe, Transportation Quarterly 54(3): 25-50.

Rhoulac, T. D. 2005. Bus or car? The classic choice in school transportation, Journal of the Transportation Research Board 1922(1): 98-104.

Ridgewell, C.; Sipe, N.; Buchanan, N. 2009. School travel modes: factors influencing parental choice in four Brisbane schools, Urban Policy \& Research 27(1): 43-57.

Rwebangira, T. 2001. Cycling in African Cities: status and prospects, World Transport Policy \& Practice 7(2): 7-10.

Spallek, M.; Turner, C.; Spinks, A.; Bain, C. 2006. Walking to school: distribution by age, sex and socioeconomic status, Health Promotion Journal of Australia 17(2): 134-138.
Srinivasan, S.; Rogers, P. 2005. Travel behaviour of lowincome residents: studying two contrasting locations in the city of Chennai, India, Journal of Transport Geography 13(3): 265-274.

Su, J.G.; Jerrett, M.; McConnell, R.; Berhane, K.; Dunton, G.; Shankardass, K.; Reynolds, K.; Chang, R.; Wolch, J. 2013. Factors influencing whether children walk to school, Health \& Place 22: 153-161.

Sub-Saharan Africa Transport Policy Program (SSATP). 2015. Policies for sustainable accessibility and mobility in urban areas of Africa. Working Paper No. 106.

Vanderschuren, M.; Jennings, G. 2017. Non-motorized travel behaviour in Cape Town, Dar es Salaam and Nairobi. In Mitullah WV, Vanderschuren M and Khayesi M (eds) Non-Motorized Transport Integration into Urban Transport Planning in Africa. New York, Routledge, 11-26.

Wilson, J.E.; Marshall, J.; Wilson, R.; Krizek, J.K. 2010. By foot, bus or car: children's school travel and school choice policy, Environment and Planning A 42(9): 2168 2185 .

Yeung, J.; Scott, W.; Andrew, P.H. 2008. Child transport practices and perceived barriers in active commuting to school, Transportation Research Part A 42(6): 895-900.

\section{jitte 401}

